\title{
Temperature changes in rheumatoid hand treated with nitrogen vapors and cold air
}

\author{
Paweł Korman • Anna Straburzyńska-Lupa • \\ Wojciech Romanowski $\cdot$ Andrzej Trafarski
}

Received: 11 February 2011 / Accepted: 21 August 2011 / Published online: 7 September 2011

(C) The Author(s) 2011. This article is published with open access at Springerlink.com

\begin{abstract}
The aim of the study was the thermovisual comparison of mean temperature of hand surface changes after local cryotherapy with vapors of nitrogen $\left(-160^{\circ} \mathrm{C}\right)$ and cold air $\left(-30^{\circ} \mathrm{C}\right)$. Forty-seven patients with rheumatoid arthritis (39 women and 8 men; average age $56.2 \pm 10.5$ years) were included in the study. They had the application of topic cryotherapy using nitrogen vapors or cold air on one hand. Main outcome measure was surface temperature of dorsal sides of the cooled and contralateral hands. Thermal images of both hands were taken before and up to $3 \mathrm{~h}$ after the treatment. One minute after application, nitrogen vapors induced decrease in surface skin temperature of the cooled hand from $28.9 \pm 1.8^{\circ} \mathrm{C}$ to $17.9 \pm 2.2^{\circ} \mathrm{C}, P<0.05$, whereas cold air from $29.4 \pm 2.4^{\circ} \mathrm{C}$ to $23.1 \pm 2.2^{\circ} \mathrm{C}, P<0.05$. However, significantly lower temperature was obtained with vapors of nitrogen $(P<0.05)$. Just after the treatment, a rapid rewarming occurred and hands reached baseline temperature in $15 \mathrm{~min}$ in both applications and they did not differ till the end of the procedure. Both nitrogen vapors and cold air induce similar temperature changes in hands
\end{abstract}

P. Korman $(\varangle) \cdot$ A. Straburzyńska-Lupa

Department of Physiotherapy, University School of Physical

Education in Poznan, Królowej Jadwigi Str. 27/39,

61871 Poznan, Poland

e-mail: simskor@interia.pl

A. Straburzyńska-Lupa · W. Romanowski

Rheumatological Centre in Srem, Mickiewicza str. 95, 63100 Śrem, Poland

A. Trafarski

Division of Metrology and Measurement Systems, Institute of Mechanical Technology, Poznan University of Technology, Poznan, pl. Marii Skłodowskiej-Curie 5, 60965 Poznan, Poland with the exclusion of temperature obtained $1 \mathrm{~min}$ after the treatment. Changes in non-cooled hands indicate contralateral reaction.

Keywords Cryotherapy · Rheumatoid arthritis . Thermography $\cdot$ Contralateral reaction $\cdot$ Rehabilitation

\section{Introduction}

Rheumatoid arthritis (RA) is a chronic inflammatory disease with joint destructive process. Most RA patients have involvement of the joints of the hand [1]. Morning stiffness, chronic pain and joint deformation cause functional disability of rheumatoid hand. Cryotherapy is most useful as an adjunct to rehabilitation program of patients with RA because of its analgetic, anti-inflammatory effects and may improve their ability to exercise [2, 3]. Nowadays, many local cryotherapy treatments using different temperatures and duration of exposition, such as ice or cold gel packs, short and intensive cold air $\left(-30^{\circ} \mathrm{C}\right)$ or vapors of nitrogen $\left(-160^{\circ} \mathrm{C}\right)$ blasts are deployed for clinical purposes $[4,5]$. Short-duration gas-blast treatments giving superficial cooling are used mostly for analgetic effect in RA patients (also outpatients) but only in hospital conditions. However, ice and gel packs are applied when deeper or more prolonged cooling is required, especially in acute musculoskeletal conditions for pain relief, inflammation and muscle spasm decrease. After taking into account all the contraindications, these modalities can also be used at home condition as a cheap and easy method of therapy [6, 7]. Hirvonen et al. [3] indicated that RA patients have significant decrease in disease activity expressed by DAS after seven day (3 times daily) of local cryotherapy (cold pack or cold air). 
Studies on physiological effects of cold stimulus show that the skin temperature decreases abruptly during the treatment and several minutes later it rapidly rises $[4,8,9]$. It is known that surface temperature changes are related to vascular reaction $[10,11]$. Considering that levels of cartilage-destroying enzymes (e.g., collagenase) produced by inflamed joints of RA patients are dependent on the temperature of local joints, it is important to answer whether cooling of the hands would additionally reduce temperature in the affected joints. There is no research concerning intraarticular effects of cryotherapy applied on hands; only there are some reports which indicate that cooling with cold air [12], nitrogen or ice packs [13] additionally reduces temperature in the affected knee joints.

Many researchers indicate lots of factors that may influence vascular reactions such as age, gender, physical fitness, smoking, cooled area, acclimatization and adaptation to cold and ambient temperature [11]. However, little is known about the effects of various cryotherapies of different temperatures on vascular reaction [14-16]. There is still not enough information explaining how the selection of cooling agent influences the after-treatment vascular reaction [17]. Consequently, the right moment to begin kinesitherapy is not properly defined [2]. It is generally believed that modalities which cause lower skin temperatures are more efficacious [18-20], but it has not been clinically proved [3].

The study was based on thermovision comparison of the temperature changes in hand surface after local cryotherapy with vapors of nitrogen $\left(-160^{\circ} \mathrm{C}\right)$ and cold air $\left(-30^{\circ} \mathrm{C}\right)$ on RA patients. The study tries to answer what treatment is more effective in inducing temperature changes and vascular reaction to cold.

\section{Materials and methods}

Forty-seven (39 women, 8 men) patients with rheumatoid arthritis voluntarily participated in the study (average age \pm standard deviation [SD], $56.2 \pm 10.5$ years). All the patients had RA diagnosis according to the standards of the American College of Rheumatology [21]. Patients with contraindications for cryotherapy or ones who did not give their consent to the examination were excluded from the research. All subjects signed informed consent accepted by the local ethical committee prior to participation in the study in accordance with the Helsinki declaration of 1975. All subjects were free from any coexistent disease that could influence the outcome. At the beginning of the procedure, one physician conducted a questionnaire to gain basic data (age, height, weight) and DAS28 (disease activity score). To establish DAS28, the number of selected swollen and tender joints was assessed (tender28 and swollen28).
The Erythrocyte Sedimentation Rate (ESR) was measured (in $\mathrm{mm} / \mathrm{h}$ ). In addition, the patients' general health on a Visual Analogue Scale (VAS) of $100 \mathrm{~mm}$ was obtained [22].

Patients were divided into two groups. The first group consisted of 23 people ( 18 women, 5 men) and underwent a treatment of cooling the hand with the vapors of liquid nitrogen, and the second group of 24 people ( 21 women, 3 men) underwent a treatment of cooling the hand with the cold air.

\section{Experimental procedure}

The day before the treatment, patients were instructed on how to observe the research procedure. On the day of the research, they were not allowed to smoke, drink alcohol or coffee and use other stimulants. Hands had to be washed and grease-free so using hand cream or ointment was forbidden. Other physical treatments as well as intensive physical activity, except for normal daily activities, were not allowed. Fifteen minute before examination and in between evaluations clenching fist, rubbing palm or having hands in pockets was also forbidden. Patients did not make any physical activity before and after the treatment.

The treatment was done only on one hand in case of each patient. Before the temperature measurement procedure, a control period was imposed for a minimum $15 \mathrm{~min}$ in an effort to allow body temperature to stabilize. First of all, pre-treatment hand temperature was measured. Patients were seated in front of the table with relaxed forearms placed on it. For repeatability of research results, patients put their hands on the mate in the special hand imprints. Pictures of dorsal sides of both hands were taken simultaneously. In the first measurement that was done before the treatment, $1-\mathrm{cm}$ alloy strap was placed and marked on the line of wrist joint in case of each patient. After that, in a treatment room (which is $10 \mathrm{~m}$ far from the measurement room), one hand of each patient was cooled.

The first group of 23 people underwent a treatment of cooling the hand with the vapors of liquid nitrogen. Temperature of the gas at the end of the nozzle was $-160^{\circ} \mathrm{C}$, and the treatment lasted for $3 \mathrm{~min}$. Gas blow was done on both sides of hand from 10 to $15 \mathrm{~cm}$ distance.

The second group of 24 people underwent a treatment of cooling the hand with the cold air. Temperature of the air at the end of $2-\mathrm{cm}$ nozzle was $-30^{\circ} \mathrm{C}$, and the treatment lasted for $3 \mathrm{~min}$. Gas blow was done on both sides of the hand from 4 to $6 \mathrm{~cm}$ distance. In the first minute of cold air treatment, there was $1000 \mathrm{l} / \mathrm{min}$ blow output in following $2 \mathrm{~min} 800 \mathrm{l} / \mathrm{min}$.

After cooling treatment, the following temperature measurements were taken. First thermogram was taken $1 \mathrm{~min}$ after the treatment and next one after 5, 15, 30, 45, 60, 120 
Table 1 Patient's characteristics, with group division

\begin{tabular}{llll}
\hline Parameter & $\begin{array}{l}\text { Group I nitrogen } \\
(n=23)\end{array}$ & $\begin{array}{l}\text { Group II cold air } \\
(n=24)\end{array}$ & $P$ \\
\hline Sex (female/male) & $18 / 5$ & $21 / 3$ & \\
Age (years), mean (range) $)$ & $56.2(36-75)$ & $56.3(34-75)$ & NS \\
BMI $\left(\mathrm{kg} / \mathrm{m}^{2}\right)$ & $26.8 \pm 3.8$ & $27.8 \pm 4.5$ & NS \\
Body temp. $\left({ }^{\circ} \mathrm{C}\right)$ & $36.7 \pm 0.2$ & $36.7 \pm 0.5$ & NS \\
DAS28 & $5.6 \pm 0.9$ & $5.4 \pm 1.2$ & NS \\
\hline
\end{tabular}

Values are mean $\pm \mathrm{SD}$

$B M I$ body mass index, $D A S 28$ disease activity score

and $180 \mathrm{~min}$ after the treatment. Both waiting and the research room had stable conditions. Room temperature was $21.5 \pm 0.5^{\circ} \mathrm{C}$ and humidity $30.7 \pm 1.8 \%$. In the research room, all sources of heat (heaters, lighting, etc.) were separated, and there was also no draft.

None of the subjects in this study reported negative reaction to the cold treatment.

\section{Instruments}

Treatments with vapors of nitrogen were done using ground device (1000 1 external container) (Institute of Molecular Physics, Polish Academy of Sciences-Poland). For cold air cooling, Cryo5 device (Zimmer-Germany) was used. Hand surface temperature was measured by thermovisual camera ThermaCAM SC 2000 (Flir-Sweden). Camera stood on the tripod, perpendicularly to the examined object. Calibration of the camera always lasted for at least $20 \mathrm{~min}$ before the first measurement.

\section{Statistical procedures}

Outcomes were presented as mean values \pm SD. $t$ test was used to evaluate mean temperature changes in cooled and non-cooled hands and also to compare analyses of mean temperatures of both groups. The statistical significance was established at the $P$ value less than 0.05 level. All analyses were performed using Statistica 5.0 package.

\section{Results}

Characteristics of the treated patients are presented in Table 1.

The treated groups did not differ in age, BMI, body temperature and disease activity score DAS28.

Mean temperatures of cooled and non-cooled hands in both groups in subsequent time intervals are presented in Fig. 1.
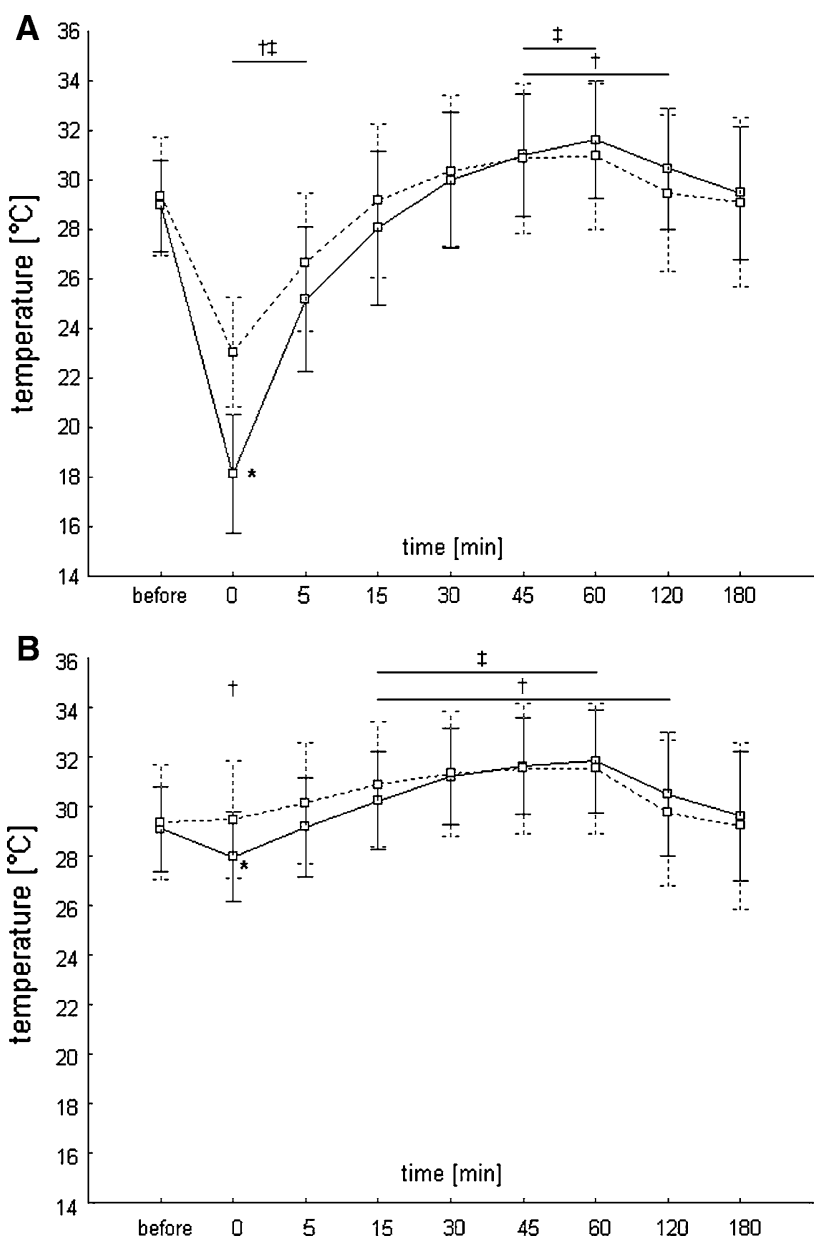

Fig. 1 Skin surface temperature of the cooled (a) and of the contralateral (b) hand during $180 \mathrm{~min}$ of trial in nitrogen vapors group (solid line) and cold air group (broken line). Data are expressed as mean with standard deviation. *Significant difference between nitrogen vapors and cold air; ${ }^{\dagger}$ significant difference from reference values (nitrogen vapors); ${ }^{*}$ significant difference from the reference values (cold air) at the $P<0.05$ level

Before the treatment, no significant differences were observed between skin surface temperatures (baseline temperature) in both groups. The mean skin surface temperatures in two groups at the end of acclimatization period were $28.9 \pm 1.8^{\circ} \mathrm{C}$ (nitrogen vapors) and $29.4 \pm 2.4^{\circ} \mathrm{C}$ (cold air) for cooled hand and $29.1 \pm 1.7^{\circ} \mathrm{C}$ (nitrogen vapors) and $29.4 \pm 2.3^{\circ} \mathrm{C}$ (cold air) for contralateral hand. The skin temperature of cooled hands decreased significantly ( $P<0.05$ vs. baseline) in response to cold application 1 min after the treatment with vapors of nitrogen and cold air (to $17.9 \pm 2.2^{\circ} \mathrm{C}$ and $23.1 \pm 2.2^{\circ} \mathrm{C}$, respectively). After $15 \mathrm{~min}$ of recovery, skin temperatures reached the baseline in both groups. In the group I (vapors of nitrogen), crucial increase in skin temperature above baseline appeared between 45 and $120 \min (P<0.05$ vs. baseline), and in the group II (cold air) between 45 and $60 \mathrm{~min}$ $(P<0.05$ vs. baseline $)$ after the treatment. 
Skin temperature of contralateral hand after the cold stimulus changes in the similar manner to cooled hand. In the group I, 1 min after the treatment, skin temperature of contralateral hand decreased significantly $(P<0.05$ vs. baseline). From that point, contralateral hands started to rewarm to reach the baseline temperature in $5 \mathrm{~min}$ after the treatment, and between $15-120 \mathrm{~min}$, the temperature increased significantly ( $P<0.05$ vs. baseline). In the group II, there was no temperature decrease below baseline in any time of measurement, and significant increase in skin temperature above baseline appeared between 15 and $60 \mathrm{~min}$ $(P<0.05$ vs. baseline $)$.

Comparing mean temperatures, significant differences between mean temperature of hand surface in both groups were noticed only just after the treatment $(P<0.05)$. Similarly significant difference in both groups between mean temperature of non-cooled hand was noticed only just after the treatment $(P<0.05)$.

\section{Discussion}

The study was conducted on RA patients because local cryotherapy has been recommended in their rehabilitation procedure. This study is the first to investigate the comparable effect of short application of vapors of liquid nitrogen and cold air on hand skin temperature of RA patients. However, the minimal skin temperature was significantly lower in the group with liquid nitrogen; in both treatments, it took 15-30 min after temperatures of hand surface reached the level before the treatment. During rewarming, no significant changes in mean value of skin temperatures of cooled and non-cooled hand in both groups were noticed. Also, we observed, like other investigators [9, 19], large individual differences in reaching minimal skin temperature, which in our investigation can be partially attributed to differences in thickness of subcutaneous tissue [23] and partially to differences in RA patient's baseline temperatures.

It is difficult to compare these results with other studies because they differ in cooling agent, observation time, application area and participants. In the research conducted by Fricke [2], treatment of cooling with cold air (-140 to $-180^{\circ} \mathrm{C}$ ) led to temperature decrease, like in the presented research, till the level of $17^{\circ} \mathrm{C}$. Return to pre-treatment temperature took $50 \mathrm{~min}$ in case of a group of healthy people and $15 \mathrm{~min}$, the same result as in our research, in a group of RA patients with high and medium disease activity. Mourot et al. [9] observed that at a group of young healthy people, at the end of $2 \mathrm{~min}$ cooling with carbon dioxide gas $\left(-78^{\circ} \mathrm{C}\right)$ on the dorsal side of hand temperature decreased to $7.3^{\circ} \mathrm{C}$ and after $15 \mathrm{~min}$ of ice bag application to $13.9^{\circ} \mathrm{C}$. One minute later, temperature rapidly increased to about $18^{\circ} \mathrm{C}$. After $20 \mathrm{~min}$ of recovery to baseline, temperature was observed and no difference in mean skin temperature between groups was noticed.

As researches of other authors show that many factors connected with the treatment have an influence on body reaction to cooling, inter alia the difference in temperatures between the cooling factor and the cooled object, also heat capacity or melting point in case of cold packs [20], duration, intensity, frequency of the factor, individual vulnerability [24], parts of the body [25].

It should be taken into consideration that there is no research which would unanimously evaluate the value of minimal skin temperature which would not cause frostbite, to get the most intensive vascular reaction at the same time. Chesterton et al. [19] show research in which different postapplication temperatures were observed after various cryotherapy modalities. Research connected with cyotherapy was most commonly undertaken in the context of the care management in musculoskeletal injuries [26, 27], rarely in the context of application in connection with exercise [26] or in case of RA patients [2]. Different methods used in tissue cooling produce different effects, long lasting cold packs cause profound effect and short cold gas blows produce reflex mechanism [24]. In case of exercise after cold application, it has to be considered that cold increased the stiffness of the collagen, resulting in a decrease in muscular flexibility [28], and influenced manual dexterity [29], which affects the performance and reduction in hand function [30].

Research on the values of temperature in the time of induced congestion is still ambiguous. Literature offers works on excessive rewarming, which is the same as in our research [2, 9], and also works in which surface temperature after the cooling treatment does not return to pre-treatment temperature for many minutes [10, 18, 31]. Our finding may indicate that in case of short and intensive cold gas blows $\left(-160^{\circ} \mathrm{C}\right.$ and $\left.-30^{\circ} \mathrm{C}\right)$ it is not important to consider to what value the tissue temperature was lowered. Similar physiological response to cold was connected with vasodilation and blood flow increase. It has been proved by Mourot [9] and Daanen [11] research.

However, it is still unknown and requires further investigation, what is an optimal skin temperature in case of short cold gas blows, which would be sufficient to reach analgetic effect and at the same time would be safe to the exercises undertaken.

Despite the fact that no comprehensive explanation of contralateral reaction was presented, there are many reports indicating, like in our findings, their presence [32-34]. Some authors suggest that the contralateral reaction is the systemic answer with cooperation of autonomous nervous system [9, 34], some of them suggest that this reaction is an peripheral spinal reflex without an influence of central thermoregulation system [35]. 
Investigation was based on thermovisual evaluation, which is acknowledged as a very useful tool in a research of hand vascular reactions [36-38]. To estimate vascular reaction, many researches choose hands because they are a very good marker of vascular changes [39], with fine set of blood vessels and great number of anastomoses, which play a significant role in thermoregulation [40]. Under the influence of the temperature, anastomoses react similarly to small arteries. During their opening, great amount of blood flows through tissues. Post-treatment changes in the tissue temperature in the presented study may suggest vascular reaction similar to the phenomenon of CIVD (cold-induced vasodilation), which is often described in the literature $[11,41]$.

However, it is worth mentioning that during rheumatoid disease vascular reaction in rheumatoid hand may differ [2]. According to Rusch et al. [42], a physiologically fast heating occurs as a result of blood flow through dilated arteries in swollen rheumatoid joints. Additionally, there is also a pathologically slower heating of blood flow in veins from deeper tissues. For that reason, research was conducted on RA patients who had inflammation of hand joints and not on healthy patients who presumably had different vascular reactions.

Obtained results allow to assume that regardless of cold stimulus temperature, it is possible to gain comparable therapeutic effect what is indicated by similar changes in hand temperature after vapors of nitrogen and cold air. Because of beneficial effect of short local cryotherapy, it is applied on joints before kinesitherapy which lasts about an hour. In our research, despite the type of cooling agent, the skin temperature was comparable for almost $3 \mathrm{~h}$ after the application.

There are some limitations we should have considered. First of all, there was no control group of healthy people. We assumed they would react for the cold stimulus in a different manner. However, the aim of the study was to compare temperature reaction in a homogeneous group for the different cold stimulus.

Another problem was that the time of trial was too long. Most of the patients in the last hour of examination had some problems with following of the strict rules of thermovisual examination. That could have an influence on the greater standard deviation in last hour temperature results.

Moreover, we did not evaluate hand temperature when the cooling application was finished because treatment room was 10 meters from research room. The result is that temperature measurement was taken $1 \mathrm{~min}$ after the end of cooling. Both those rooms were purposely separated to exclude the influence of cooling factors on thermovisual research.

\section{Conclusion}

Our findings are important in the clinical use of cold gas blows before kinesitherapy. Presented results seem to indicate that during short 3 -min cold application $\left(-160^{\circ}\right.$ and $-30^{\circ} \mathrm{C}$ ) on hands, the intensity of cooling at the minimal temperature measured after the treatment does not influence vascular reaction. This can suggest that, irrespectively of the deployed cooling agent, kinesitherapy conducted after the treatment was in the comparable conditions of increased blood flow of tissues.

Acknowledgments We are grateful to Jan Chajda, PhD, and Leszek Różański, PhD, from the Division of Metrology and Measurement Systems in Institute of Mechanical Technology Poznan University of Technology for offering thermovisual camera and help in taking measures.

Conflicts of interest The authors have no conflicts of interest to declare.

Open Access This article is distributed under the terms of the Creative Commons Attribution Noncommercial License which permits any noncommercial use, distribution, and reproduction in any medium, provided the original author(s) and source are credited.

\section{References}

1. Wessel J (2004) The effectiveness of hand exercise for persons with rheumatoid arthritis: a systematic review. J Hand Ther 17(2):174-180

2. Fricke R (1984) Lokale Kaltlufttherapie- eine weitere kryotherapeutische Behandlungsmethode. Z Phys Med Baln Med Klim 13:260-266

3. Hirvonen EH, Mikkelsson KM, Kautiainen H et al (2006) Effectiveness of different cryotherapies on pain and disease activity in active rheumatoid arthritis. A randomised single blinded controlled trial. Clin Exp Rheumatol 24:295-301

4. Knight KL (1995) Cryotherapy in sport injury management. Human Kinetics, Champaign, IL

5. Fricke R (1988) Lokale Kryotherapie bei chronisch entzündlichen Gelenkerkrankungen 3-4 mal täglich. Z Phys Med Baln Med Klim 17:196-202

6. Tepperman SP, Devlin M (1986) The therapeutic use of local heat and cold. Can Fam Physician 32:1110-1114

7. Fedorczyk J (1997) The role of physical agents in modulating pain. J Hand Ther 10:110-121

8. Jutte SL, Merrick AM, Ingersoll DC et al (2001) The relationship between intramuscular temperature, skin temperature and adipose thickness during cryotherapy and rewarming. Arch Phys Med Rehabil 82:845-850

9. Mourot L, Cluzeau C, Regnard J (2007) Hyperbaric gaseous cryotherapy: effects on skin temperature and systemic vasoconstriction. Arch Phys Med Rehabil 88:1339-1343

10. Pollock EF, Koman AL, Smith PB et al (1993) Measurement of hand microvascular blond flow with isolated cold stress testing and laser Doppler fluxmetry. J Hand Surg 18A(1):143-150

11. Daanen MAH (2003) Finger cold-induced vasodilation: a review. Eur J Appl Physiol 89:411-442 
12. Kim YH, Baek SS, Choi KS et al (2002) The effect of cold air application on intra-articular and skin temperatures in the knee. Yonsei Med J 43(5):621-626

13. Oosterveld FG, Rasker JJ (1994) Treating arthritis with locally applied heat or cold. Semin Arthritis Rheum 24(2):82-90

14. Weston M, Taber C, Casagranda L et al (1994) Changes in local blood volume during cold gel pack application to traumatized ankles. J Orthop Sports Phys Ther 19:197-199

15. Kakitsuba N, Nakayama H (1996) Evaluation on rebound effects when the forearm was exposed to cold air. J Occup Health 38(5):211-216

16. Sawada S, Araki S, Yokoyama K (2000) Changes in cold-induced vasodilation, pain and cold sensation in fingers caused by repeated finger cooling in a cool environment. Ind Health 38(1):79-86

17. Sapega AA, Heppenstall BR, Sokolow PD et al (1988) The bioenergetics of preservation of limbs before replantation. J Bone Joint Surg Am 70-A(10):1500-1511

18. Bugaj R (1975) The cooling, analgesic, and rewarming effects of ice massage on localized skin. Phys Ther 55:11-19

19. Chesterton SL, Foster EN, Ross L (2002) Skin temperature response to cryotherapy. Arch Phys Med Rehabil 83:543-549

20. Merrick MA, Jutte LS, Smith ME (2003) Cold modalities with different thermodynamic properties produce different surface and intramuscular temperatures. J Athl Train 38:28-33

21. Arnett FC, Edworthy SM, Bloch DA et al (1988) The American Rheumatism Association 1987 revised criteria for the classification of rheumatoid arthritis. Arthritis Rheum 31:315-324

22. Prevoo ML, van't Hof MA, Kupper HH et al (1995) Modified disease activity scores that include twenty-eight-joint counts. Development and validation in a prospective longitudinal study of patients with rheumatoid arthritis. Arthritis Rheum 38:44-48

23. Otte JW, Merrick MA, Ingersoll CD et al (2002) Subcutaneous adipose tissue thickness alters cooling time during cryotherapy. Arch Phys Med Rehabil 83:1501-1505

24. Bochdansky Th, Sadil V, Fialka V et al (1988) Physikalische Untersuchungen zur differenzierten Beurteilung von Kryotherapieverfahren. Z Phys Med Baln Med Klim 17:203-216

25. Jansky L, Vavra V, Jansky P et al (2003) Skin temperature changes in humans induced by local peripheral cooling. J Thermal Biol 28(5):429-437

26. Swenson C, Swärd L, Karlsson J (1996) Cryotherapy in sports medicine. Scand J Med Sci Sports 6:193-200

27. Collins NC (2008) Is ice right? Does cryotherapy improve outcome for acute soft tissue injury? Emerg Med J Feb 25(2): $65-68$
28. Grana W (1994) Cold modalities. In: DeLee J, Drez D (eds) Orthopaedic sports medicine: principles and practice. WB Saunders Co., Philadelphia, pp 203-207

29. Heus R, Daanen HAM, Havenith G (1995) Physiological criteria for functioning of hands in the cold. Appl Ergon 26(1):5-13

30. Kauranen K, Vanharanta H (1997) Effects of hot and cold packs on motor performance of normal hands. Physiotherapy 83(7):340 344

31. Kanlayanaphotporn R, Janwantanakul P (2005) Comparison of skin surface temperature during the application of various cryotherapy modalities. Arch Phys Med Rehabil 86:1411-1415

32. Meehan PJ (1957) General body cooling and hand cooling. In: Fisher RF (eds) Protection and functioning of the hands in cold climates. Washington, pp 45-57

33. Crossland S, Drysdale I (2006) Investigation into affectivity on cutaneous blond perfusion of different application time lengths of cold hydrotherapy. Int J Osteopath Med 9:27-46

34. Cook JP, Creager MA, Osmundson PJ et al (1990) Sex differences in control of cutaneous blood flow. Circulation 82:1607-1615

35. Pulst S, Haller P (1981) Thermographic assesment of impaired sympathetic function in peripheral nerve injuries. J Neurol 226:35-42

36. Jones BF (1998) A reappraisal of the use of infrared thermal image analysis in medicine. IEEE Trans Med Imaging 17(6):1019-1027

37. Zaproudina N, Ming Z, Hänninen POO (2006) Plantar infrared thermography measurements and low back pain intensity. J Manipulative Physiol Ther 29:219-223

38. Haake M, Willenberg T, Sauer F et al (2002) Effect of extracorporeal shockwave therapy on vascular regulation. Infrared thermography in epicondylitis humeri radialis. Swiss Surg 8:176-180

39. Stansberry BK, Peppard RH, Babyak ML et al (1999) Primary nociceptive afferents mediate the blond flow dysfunction in nonglabrous (Hairy) Skin of Type 2 Diabetes. Diabetes Care 22(9):1549-1554

40. Clark RE, Clark LE (1934) Observations on living arterio-venous anastomoses as seen in transparent chambers introduced into the rabbit's ear. Am J Anat 54(2):229-284

41. Sawada S (1996) Cold-induced vasodilatation response of finger skin blond vessels in older men observed by using a modified local cold tolerance test. Ind Health 34:51-56

42. Rusch D, Follmann M, Boss B et al (2000) Dynamic thermography of the knee joints in the rheumatoid arthritis (RA) in the course of the first therapy of the patient with methylprednisolone. Z Rheumatol 59(Suppl. 2):131-135 